\title{
SMART MIRROR BERBASIS RASPBERRY PI 4 UNTUK HOME AUTOMATION
}

\author{
Aldo Dwi Pasetya ${ }^{1}$, M. Daffa Raihan Ma'arif ${ }^{2}$, Shania Syaharani ${ }^{3}$, Imam Halimi ${ }^{4}$, Dezetty \\ Monika $^{5}$
}

\author{
1,2,3,4,5 Politeknik Negeri Jakarta, Jurusan Teknik Elektro, Prodi Teknik Listrik \\ Jl. Prof. DR. G.A.Siwabessy, Kampus Baru UI Depok, 16425, Indonesia
}

Fax: (021) 7270034

\author{
email : aldodwiprasetya1999@gmail.com ${ }^{1}$ \\ imam_halimi@yahoo.co.id ${ }^{4}$
}

\begin{abstract}
Smart Mirror is a two-way mirror with an electronic display behind the glass. Smart Mirror can display various types of information in the form of widgets and will be useful for individuals who want to multitask and stay informed. This tool can be controlled by voice command or by touching the IR Frame to activate the voice detector. To find out whether this tool is functioning, a testing method is carried out by looking at the system and the overall process on the tool starting from the Smart Mirror graphic display, supporting sensor functions, component functions, and the Voice Assistant function as Home Automation. Where each of these tests has different stages depending on what will be tested. Then the results obtained that the Smart Mirror graphic display, supporting sensor functions, component functions, and the Voice Assistant function as Home Automation can function properly. However, in the measurement of air humidity there is an error where the measured data is not readable. For the length of time the load responds to a command. Each load used in this study can successfully respond to commands with a time duration of between $5-8.5$ seconds. Where, the load that responds the fastest to the command is the Bardi brand lamp and the load that takes the longest to respond to the command is switch 2.
\end{abstract}

Keywords:Smart Mirror; IR Frame ; Voice Detector; Home Automation

\begin{abstract}
ABSTRAK
Smart Mirror merupakan cermin dua arah dengan tampilan elektronik di belakang kaca. Smart Mirror dapat menampilkan berbagai jenis informasi dalam bentuk widget dan akan berguna bagi individu yang ingin melakukan banyak tugas dan tetap mendapat informasi. Alat ini dapat dikontrol dengan voice command atau dengan berupa sentuhan pada IR Frame untuk mengaktifkan voice detector. Untuk mengetahui apakah alat ini berfungsi dilakukan metode pengujian dengan melihat sistem dan proses secara keseluruhan pada alat dimulai dari tampilan grafis Smart Mirror, fungsi sensor pendukung, fungsi komponen, dan fungsi Voice Assistant sebagai Home Automation. Dimana masing-masing pengujian tersebut memiliki tahapan yang berbeda-beda tergantung dengan apa yang akan diuji. Kemudian didapatkan hasil bahwa tampilan grafis Smart Mirror, fungsi sensor pendukung, fungsi komponen, dan fungsi Voice Assistant sebagai Home Automation dapat berfungsi dengan baik. Namun, pada pengukuran kelembapan udara terdapat kesalahan dimana data yang terukur tidak terbaca. Untuk durasi lamanya waktu dari beban merespon adanya perintah. Masing-masing beban yang digunakan pada penelitian ini dapat berhasil merespon adanya perintah dengan durasi waktu antara 5 8,5 detik. Dimana, beban yang paling cepat merepon perintah ialah lampu merk Bardi dan beban yang paling lama untuk merespon perintah ialah saklar 2 .
\end{abstract}

Kata kunci: Cermin Pintar; IR Frame ; Voice Detector; Home Automation 


\section{PENDAHULUAN}

Perkembangan teknologi pada masa sekarang banyak menciptakan alat yang dapat mempermudah manusia dalam melakukan berbagai aktifitas. Salah satu hasil perkembangan teknologi tersebut ialah terciptanya sebuah cermin yang disebut Smart Mirror. Smart Mirror adalah cermin dua arah dengan tampilan elektronik di belakang kaca [1]. Dimana cermin ini dapat menampilkan berbagai informasi mulai dari berita terkini, perkembangan kasus Covid-19, prakiraan cuaca dan lainlain. Selain itu juga dapat membantu manusia dalam penggunaan berbagai peralatan listrik yang terintegrasi dengan koneksi internet.

Smart Mirror memiliki basis operasi Raspberry Pi 4 dengan menggunakan perintah suara untuk mengoperasikan alat tersebut [2]. Raspberry $P i$ adalah komputer seukuran kartu kredit yang mudah diprogram dan digunakan bahkan untuk orang yang tidak memiliki latar belakang TI [3]. Penggunaan Raspberry $P i$ sebagai basis operasi dimaksudkan untuk memperkecil penggunaan ruang dalam pembangunan alat. Selain itu, penggunaan Raspberry Pi juga dimaksudkan untuk memudahkan dalam penggunaan fungsi komputer secara lebih kompleks dalam sistem yang lebih ringan dan simpel.

Sebuah pengaturan alat dan berbagai kegiatan Home Automation tidak luput dari sistem integrasi internet. Hal ini menuntun pada sebuah sistem kerja yang dikenal dengan nama Internet of Things (IoT). Internet of things (IoT) adalah adalah sensor-sensor yang terhubung ke internet dan berperilaku seperti internet dengan membuat koneksi-koneksi terbuka setiap saat, serta berbagi data secara bebas dan memungkinkan aplikasi-aplikasi yang tidak terduga, sehingga komputer-komputer dapat memahami dunia di sekitar mereka dan menjadi bagian dari kehidupan manusia [4].

Sebuah sistem kerja yang berintegrasi dengan koneksi internet mampu memiliki efisiensi dan efektivitas kerja yang jauh lebih baik. Hal ini dapat ditunjukkan dengan pengambilan data informasi secara real time, pengontrolan alat dengan tanpa batasan jarak, komunikasi tanpa batasan jarak, dan berbagai hal lainnya. Kemampuan tersebut dapat terjadi dikarenakan sistem API.

Application Programming Interface (API) adalah suatu kumpulan instruksi program yang digunakan untuk membangun suatu aplikasi perangkat lunak [5]-[7]. Aplication Programming Interface (API) memfasilitasi untuk seuatu pertukaran informasi atau data antara dua atau lebih aplikasi perangkat lunak. Sebuah Aplication Programming Interface (API) berperan sebagai pembawa pesan yang dikirim oleh client atau pengguna yang selanjutnya akan memberi tahu suatu sistem apa yang harus dilakukan sistem tersebut, kemudian sistem akan memberikan respon balik yang sesuai dengan permintaan client atau pengguna. Dimana sistem kerja yang diterapkan disini menggunakan sistem kerja Voice Assistant. Voice Assistant merupakan asisten digital yang menggunakan pengenalan suara, atau pun juga Natural Language Processing (NLP) untuk menjalankan perintah yang diperintahkan oleh pengguna [8]-[10].

Penelitian ini dilakukan untuk mengetahui apakah alat sudah dapat berfungsi sesuai deskripsi dan juga melihat berapa lama waktu yang dibutuhkan oleh alat ini untuk merespon perintah yang diucapkan. Selain itu, penelitian ini sendiri dimaksudkan untuk melihat kapabilitas dari penggunaan Smart Mirror dan diharapkan bahwa alat ini mampu diterapkan di berbagai sektor seperti penggunaan perumahan (pribadi), komersil, kesehatan, pendidikan, industry, olahraga, dsb nya dengan penyesuaian dalam beberapa hal seperti pada bagian komponen, pemrograman, widget, dsb nya sesuai dengan kebutuhan dari masing-masing sektor tersebut. 


\section{METODE PENELITIAN}

Diagram blok sistem kerja dari Smart Mirror berbasis Raspberry Pi 4 untuk Home Automation ini sendiri dapat dilihat pada Gambar 1. Proses penggunaan suara dalam memberikan perintah pengontrolan alat pada Smart Mirror dapat dilihat pada Gambar 2. Dapat dilihat yaitu saat melakukan start, terdapat dua pilihan jenis masukan, yaitu dengan voice command atau berupa sentuhan pada IR Frame untuk mengaktifkan voice detector. Setelah voice command yang diberikan dideteksi oleh voice detector, akan dihasilkan dua kemungkinan:

1) Apabila suara tidak terdeteksi, maka proses diulang.

2) Apabila suara terdeteksi, maka akan proses berlanjut.

Saat raspberry pi 4 memproses perintah, akan dihasilkan dua kemungkinan:

1) Apabila perintah yang diberikan salah, proses input diulang.

2) Apabila perintah yang diberikan benar, maka hasilnya akan dikirimkan ke web server dengan komunikasi client-server.

Selanjutnya, perintah diproses pada web service, akan menghasilkan dua keumungkinan:

1) Apabila proses gagal, maka akan kembali ke web server.

2) Apabila proses berhasil, maka perintah pengontrolan akan dikirim dengan sistem API, setelah itu keluaran suara muncul pada speaker dan alat akan terkontrol.

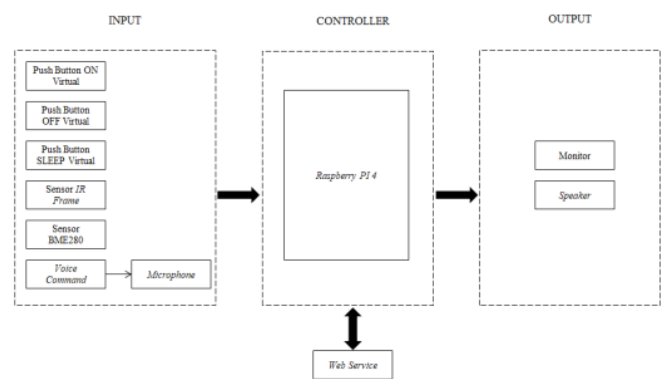

Gambar 1 Diagram blok Smart Mirror Berbasis Raspberry Pi 4

Langkah-langkah yang dilakukan adalah:

1. Aktifkan script Smart Mirror dengan command cd MagicMirror/npm start
2. Perhatikan apakah terjadi kerusakan atau kesalahan sistem dan program saat Smart Mirror sedang running program.

3. Aktifkan Voice Detector dengan menyebutkan kata kunci "Jarvis".

4. Ucapkan perintah suara untuk memberikan instruksi terhadap modul Voice Assistant.

5. Lihat respons Voice Assistant terhadap perintah yang diberikan.

6. Lihat respons alat yang dikontrol.

7. Catat waktu berapa lama alat merespon perintah yang diberikan.

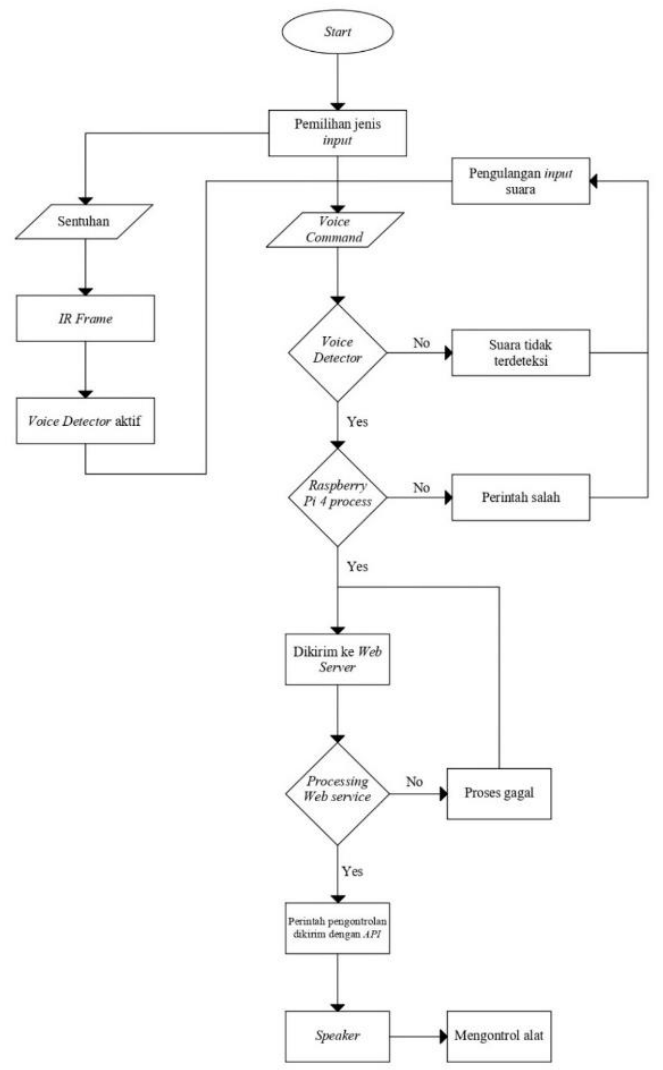

Gambar 2 Flowchart Voice Assistant untuk Home Automation

\section{HASIL dan PEMBAHASAN}

\section{A. Data hasil pengujian}

Hasil dari data pengujian didapat dengan melihat sistem dan proses secara keseluruhan pada alat dimulai dari tampilan grafis Smart Mirror, fungsi sensor pendukung, fungsi komponen, dan fungsi Voice Assistant sebagai Home Automation. Hasil 
tampilan saat pengujian dapat dilihat pada Gambar 3.

\section{B. Tampilan grafis Smart Mirror}

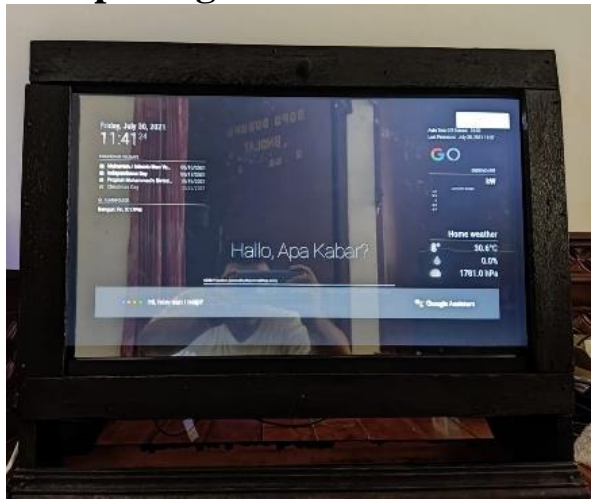

Gambar 3. Tampilan Smart Mirror

Pada pengujian tampilan grafis ini menandakan program yang dibuat telah sesuai dengan tata bahasa phyton.

\section{Fungsi sensor pendukung}

Pada pengujian fungsi sensor pendukung yaitu IR Frame ini menandakan program yang dibuat telah sesuai dengan tata bahasa phyton.

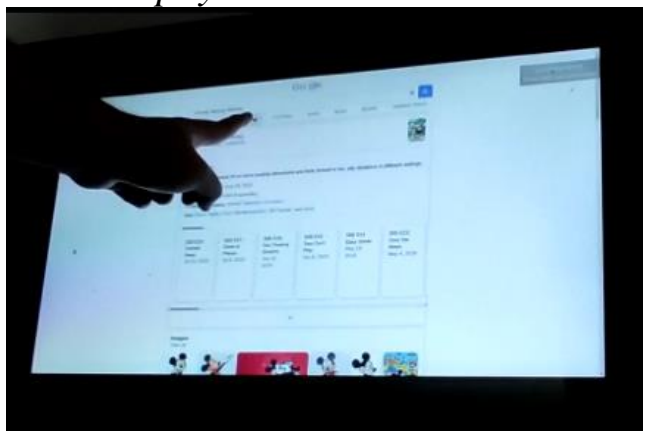

Gambar 4. IR Frame

Pada pengujian fungsi sensor pendukung yaitu Sensor BME280 ini menandakan program yang dibuat telah sesuai dengan tata bahasa phyton. Kemudian hasil pengukuran dari Sensor BME280 dapat dilihat pada Tabel 1.

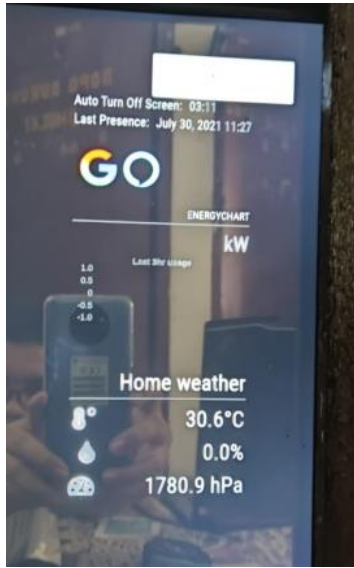

Gambar 5. Sensor BME280

Tabel 1. Hasil pengukuran data oleh sensor BME280

\begin{tabular}{cccc}
\hline $\begin{array}{c}\text { Waktu } \\
(\text { menit })\end{array}$ & $\begin{array}{c}\text { Kelembapan } \\
\text { Udara }(\%)\end{array}$ & $\begin{array}{c}\text { Suhu } \\
\left({ }^{\circ} \mathrm{C}\right)\end{array}$ & $\begin{array}{c}\text { Tekanan } \\
\text { Udara } \\
(\mathrm{hPa})\end{array}$ \\
\hline 5 & 0 & 30.6 & 1780.9 \\
10 & 0 & 30.8 & 1781.1 \\
15 & 0 & 31.1 & 1781.2 \\
\hline
\end{tabular}

Dapat dilihat dari Tabel 1. bahwa pada data pengukuran suhu dan tekanan udara sensor dapat bekerja dengan baik. Namun terdapat kesalahan pada data pengukuran kelembapan udaranya, dimana pada percobaan hasil menunjukkan nilai 0 berturut-turut. Kesalahan ini bisa ditimbulkan dari kesalahan pada saat menghubungkan pin out sensor dengan menggunakan solder.

\section{Fungsi komponen}

Dapat dilihat dari Tabel 2. bahwa semua komponen yang digunakan pada Smart Mirror dapat berfungsi sebagaimana mestinya. Juga dapat saling berintegrasi satu dengan yang lainnya.

Tabel 2. Hasil pengujian komponen yang digunakan pada Smart Mirror

\begin{tabular}{|c|l|l|}
\hline No. & \multicolumn{1}{|c|}{ Pengujian } & Kondisi Komponen \\
\hline 1 & Monitor & $\begin{array}{l}\text { Dapat berfungsi } \\
\text { dengan baik }\end{array}$ \\
\hline 2 & Raspberry Pi 4 & $\begin{array}{l}\text { Dapat berfungsi } \\
\text { dengan baik }\end{array}$ \\
\hline 3 & $\begin{array}{l}\text { Mikrofon dan } \\
\text { Pengeras Suara }\end{array}$ & $\begin{array}{l}\text { Dapat berfungsi } \\
\text { dengan baik }\end{array}$ \\
\hline 4 & USB Extension & $\begin{array}{l}\text { Dapat berfungsi } \\
\text { dengan baik }\end{array}$ \\
\hline
\end{tabular}




\section{E. Fungsi Voice Assistant sebagai Home Automation}

Untuk hasil pengujian pada masingmasing beban dapat diihat pada Tabel 3. Tabel 6.

Tabel 3. Hasil pengujian voice assistant unruk pengontrolan lampu merk Bardi

\begin{tabular}{cc}
\hline \multicolumn{2}{c}{ Lampu Bardi } \\
\hline Perintah & Respons \\
\hline Nyalakan & Lampu menyala \\
Matikan & Lampu mati \\
Redupkan ke & Kecerahan \\
$10 \%$ & lampu ke 10\% \\
Ubah warna & Warna lampu \\
ke merah & berubah menjadi \\
& merah
\end{tabular}

Dapat dilihat Tabel 3. pada beban lampu merk Bardi, dilihat saat perintah 'Nyalakan', maka lampu menyala, saat perintah 'Matikan', maka lampu mati. Selain itu dapat pula dilakukan pengontrolan terhadap warna lampu seperti mengganti warna lampu menjadi merah dengan perintah 'Ubah warna lampu menjadi merah'.

Tabel 4. Hasil Pengujian Pengontrolan Beban Intalasi Sederhana

\begin{tabular}{cc}
\hline \multicolumn{2}{c}{ Instalasi Sederhana } \\
\hline Perintah & Respons \\
\hline Nyalakan & Lampu 1 \\
Saklar 1 & menyala \\
Matikan Saklar & Lampu 1 \\
1 & mati \\
Nyalakan & Lampu 2 \\
Saklar 2 & menyala \\
Matikan Saklar & Lampu 2 \\
2 & mati \\
\hline
\end{tabular}

Dapat dilihat dari Tabel 4. bahwa saat perintah 'Matikan' dan 'Nyalakan' untuk saklar satu ataupun dua terdeteksi oleh Voice Assistant, lampu merespons juga dengan keadaan menyala dan mati sesuai perintah.

Tabel 5. Hasil Pengujian Pengontrolan Beban Kipas

\begin{tabular}{cc}
\hline \multicolumn{2}{c}{ Kipas } \\
\hline Perintah & Respons \\
\hline Nyalakan & Lampu 1 \\
Kipas & menyala
\end{tabular}

Matikan Lampu 1 mati Kipas

Dapat dilihat dari tabel 5. bahwa saat perintah 'Matikan' dan 'Nyalakan' untuk kipas terdeteksi oleh Voice Assistant, maka kipas akan merespons dengan keadaan menyala dan mati sesuai perintah.

Tabel 6. Respons Waktu

\begin{tabular}{cc}
\hline Alat yang dikontrol & $\begin{array}{c}\text { Lama Alat } \\
\text { Merespons }\end{array}$ \\
\hline Lampu merk Bardi & \pm 5 detik \\
Instalasi Sederhana: & \\
1. Saklar 1 & \pm 7 detik \\
2. Saklar 2 & \pm 8 detik \\
Kipas & \pm 6.5 detik \\
\hline
\end{tabular}

Dapat dilihat dari Tabel 6. bahwa respons waktu alat terhadap pengontrolan alat berkisar anatara 2 hingga 5 menit.

\section{KESIMPULAN}

Dari penelitian yang telah dilakukan dapat disimpulkan:

1. Smart Mirror berhasil bekerja sesuai dengan deskripsi dimana tampilan grafis Smart Mirror, fungsi sensor pendukung, fungsi komponen, dan fungsi Voice Assistant sebagai Home Automation dapat berfungsi dengan baik.

2. Pada pengukuran kelembapan udara terdapat kesalahan dimana data yang terukur tidak terbaca.

3. Durasi lamanya waktu dari beban merespon adanya perintah. Masingmasing beban yang digunakan pada penelitian ini dapat berhasil merespon adanya perintah dengan durasi waktu antara $5-8,5$ detik.

4. Beban yang paling cepat merepon perintah ialah lampu merk Bardi dan beban yang paling lama untuk merespon perintah ialah saklar 2 .

\section{DAFTAR PUSTAKA}

[1] Illinois Institute of Technology. (2016). Smart Lab, "Information Technology and Management Project". Diakses pada 10 Agustus 2021, dari 
https://appliedtech.iit.edu/smartlab-information-technology-andmanagement/projects/smartmirror

[2] BPPTIK. (2014). "Mengenal Lebih Dekat Raspberry Pi". Diakses pada 10 Agustus 2021, dari https://bpptik.kominfo.go.id/2014 /04/14/410/mengenal-lebih-dekatraspberry-pi/

[3] B., Santosh, et. al. (2019). "Smart Mirror". International Research Journal of Engineering and Technology (IRJET). 6(5)

[4] Youtube. (2018). Kevin Ashton, "Inventor of IoT - LiveWorx 2018". Diakses pada 10 Agustus 2021 , dari https://www.youtube.com/watch? $\mathrm{v}=\mathrm{N} 3 \mathrm{fQGSOMnaY}$

[5] Constantin, Yoshua, Ucuk Darusalam, Novi Dian Nathasia. (2020). "Aplikasi Pe..rsonal Assistant Berbasis Voice Command Pada Sistem Operasi Android Dengan NLP". JOINTECS, Vol. 5, No. 2, (2020), $121-128$.

[6] Dhamanigi, Joshua Roshan, et all. (2017). "Smart Mirror - A Home Automation System Implemented Using Ambient Artificial Intelligence". International Journal of Innovative Research in Science, Engineering and Technology, U.G. Research Scholar, Department of Computer Science and Engineering, New Horizon College of Engineering, Bangalore, India, Vol. 6, Issue 7, July 2017.

[7] Erick Fernando. (2014). "Automatisasi Smart Home Dengan Raspberry Pi dan Smartphone Android". Konferensi Nasional Ilmu Komputer (KONIK) 2014.

[8] Hartono, Felix, Resmana Lim, \& Lily Puspa Dewi. (2020).
"Pembuatan Sistem Rumah Pintar dengan Voice Assistant di Raspberry Pi”. Jurnal Infra, Vol 18, No.1.

[9] Puthran, R., Patil, A., Kadam, M., \& Patil, N. (2020). "Iot Based Smart Mirror using Raspberry Pi”. 2010-2019 S-JPSET, 137-141.

[10] Qorni, Wais Al. (2018). Rancang "Bangun Smart Home Menggunakan Raspberry $\mathrm{Pi} 3$ dengan Control Berbasis Web". Skripsi thesis, Universitas Islam Negeri Syarif Hidayatullah. 